\title{
Aromatase Inhibitors as Neoadjuvant Treatment in Elderly Patients with Locally Advanced Breast Cancer
}

\author{
Lucia Borgato, ${ }^{1}$ Antonella Brunello, ${ }^{1}$ Vittorina Zagonel, ${ }^{2}$ Tania Saibene ${ }^{3}$ and Silvia Michieletto \\ 1. Oncologist, Medical Oncology Unit 1; 2. Director of Medical Oncology, Medical Oncology Unit 1; \\ 3. Surgeon, Surgical Oncology Unit, Veneto Oncological Institute, IRCCS Padova, Italy
}

\begin{abstract}
Pre-operative volume reduction of locally advanced breast cancers (LABC) is an issue of great importance when approaching elderly women, who often present with extensive disease along with a burden of co-morbidity which increases the risk of complications and mortality from treatment. A comprehensive geriatric evaluation is a necessary requirement before recommending any treatment in older patients. Endocrine treatment in the neoadjuvant setting allows disease control and downstaging of tumours and is fairly well tolerated. Tamoxifen has been the mainstay of endocrine therapy for patients unable to undergo surgery, but resistance eventually develops. Aromatase inhibitors (Als) are superior to tamoxifen in this setting, with greater downstaging of the tumour and disease control. Als are now the treatment of choice in elderly patients with oestrogen receptor-positive breast cancer who are being considered for neoadjuvant endocrine therapy. There are some data that definitive treatment with an Al for LABC in unfit patients may guarantee long-term control of disease.
\end{abstract}

\section{Keywords}

Neoadjuvant therapy, endocrine treatment, breast cancer, elderly patients, aromatase inhibitors

Disclosure: The authors have no conflicts of interest to declare.

Received: 12 January 2012 Accepted: 24 January 2012 Citation: European Oncology \& Haematology, 2012;8(3):184-8 DOI: 10.17925/EOH.2012.08.3.184

Correspondence: Lucia Borgato, Medical Oncology 1, Veneto Oncological Institute, IRCCS, Via Gattamelata 64, 35128 Padova, Italy. E: lucia.borgato@gmail.com

Breast cancer is the most common type of cancer in the female population worldwide, with an estimated incidence of more than 1.3 million new cases and 458,000 deaths in $2008 .{ }^{1}$ Up to $30 \%$ of breast cancers are reported to occur in women aged 70 years or over; ${ }^{2,3}$ however, due to the under-representation of elderly patients in cancer clinical trials, 4,5 there are few data to help define the optimum treatment for these patients.

A retrospective study of trials submitted to the US Food and Drug Administration (FDA) for drug approval in the years 1995-2002 showed that the percentage of women aged 65 years and over enrolled in clinical trials of hormonal therapy for breast cancer closely matched the proportion of breast cancer patients of the same age in the US, but inclusion rates in chemotherapy trials are much lower. ${ }^{6}$ Although the elderly population is heterogeneous, 65 years does not seem to be the optimum threshold for defining an elderly patient, and most of the members of a National Comprehensive Cancer Network (NCCN) taskforce for breast cancer in the elderly agreed to set 70 years as a better cut-off point. ${ }^{7}$

Locally advanced breast cancer ( $\mathrm{LABC}$ ) refers to patients diagnosed with large primary cancers and/or regional adenopathy. Its frequency has diminished greatly thanks to screening mammography and early detection. However, there are some populations, such as women in low-income countries or elderly women in industrialised countries, who continue to experience disproportionately high breast cancer mortality rates, as they are at an increased risk of having locally advanced disease at diagnosis. Data show that the frequency of $\angle A B C$ is indeed higher in elderly women, with $10 \%$ of cases occurring in patients younger than 40 years but $30 \%$ occurring in patients aged 70 years or over. ${ }^{8-10}$

In oestrogen receptor-positive (OR+) tumours, hormonal therapy has been shown to have only minor toxicity and similar activity compared to chemotherapy, ${ }^{11}$ which makes it a very attractive option for elderly patients with locally advanced or extensive disease not amenable to breast-conserving surgery (BCS). Wyld et al. reported that $40 \%$ of women with breast cancer aged 70 years or over were receiving pre-operative endocrine therapy in the UK in 2002. ${ }^{12}$

Tamoxifen has been the mainstay of endocrine therapy for $\mathrm{OR}+$ breast cancer for more than 30 years, beyond being the first drug to be used in the neoadjuvant setting for elderly or frail patients unable to undergo surgery or more toxic therapies..$^{13-15}$

It has been demonstrated that, for post-menopausal and elderly women with large breast tumours (more than $3 \mathrm{~cm}$ ) and expression of oestrogen receptors, the administration of a third-generation aromatase inhibitor (Al) for some months results in a more consistent tumour volume reduction than is obtained with tamoxifen, ${ }^{16-18}$ allowing BCS to be performed in most cases. ${ }^{19}$

There are three approved and currently available hormonal agents: the non-steroidal Als letrozole and anastrozole and the steroidal Al exemestane. So far, all Als have been demonstrated to be more effective than tamoxifen and, in a recently published randomised 
trial, they have been shown to be biologically equivalent, as neoadjuvant treatment, to tamoxifen. ${ }^{20}$ Although there are no statistical differences in overall survival (OS) between tamoxifen and $A l s,{ }^{21,22}$ progression-free survival (PFS) is better in patients who have been treated with an $\mathrm{Al}^{23,24}$

Several trials have assessed the efficacy and safety of neoadjuvant endocrine therapy using Als in post-menopausal patients with breast cancer. Trials considering the three available drugs are discussed below under the relevant drug. Activity data for the Als used in these trials are presented in Table 1.

Overall, side effects induced by currently prescribed Als are similar for all Als combined, displaying an 'Al class effect' pattern of adverse events. These adverse events comprise hot flushes, nausea, diarrhoea and vomiting, arthralgias/myalgias that often give rise to a polymyalgia-like syndrome, blood lipid disorders (with hypercholesterolaemia and/or hypertriglyceridaemia) and loss of bone mass (with a higher risk of bone fractures and worsening of osteoporosis). When compared with other endocrine treatment, however, there is, with Als, a decreased risk of vaginal bleeding and of thromboembolic events. ${ }^{25-28}$

\section{Letrozole}

Letrozole (4,4'-[1 $\mathrm{H}-1,2,4$-triazol-1-ylmethylene]bis-benzonitrile) is an orally administered non-steroidal competitive aromatase enzyme inhibitor that has been shown to be more effective than tamoxifen in terms of response rate and time to progression as first-line treatment for post-menopausal women with locally advanced and metastatic breast cancer. ${ }^{29,30}$ Research about the efficacy of letrozole in the pre-operative setting is increasing.

The large randomised controlled trial P024 compared letrozole $2.5 \mathrm{mg}$ versus tamoxifen $20 \mathrm{mg}$ for four months as neoadjuvant treatment for post-menopausal women with oestrogen- and/or progesterone-positive (OR/PR+) untreated primary breast cancer. ${ }^{31}$ Three hundred and thirty-seven patients were enrolled and a significantly higher overall response rate, evaluated by clinical palpation, was reported in the letrozole arm (55\% versus $36 \%$, $\mathrm{p}<0.001)$, with fair tolerance in both arms. Treatment response was also assessed by ultrasound and mammograms, which confirmed the better results with letrozole. Notably, there was a lower rate of BCS in the tamoxifen group than in the letrozole group (35\% versus $45 \%$, $\mathrm{p}=0.002$ ). The median age of patients treated with letrozole was 68 years and both study arms included a high proportion of patients aged 70 years or over ( $46 \%$ in the letrozole arm and $42 \%$ in the tamoxifen arm). A subanalysis to investigate the correlation between age ( $<70$ years, $\geq 70$ years) and objective response was conducted but did not show any significant results.

Dixon et al..$^{32}$ investigated the possibility of a different antitumour activity of letrozole when used at a daily dose of $2.5 \mathrm{mg}$, compared with a daily dose of $10 \mathrm{mg}$, as primary neoadjuvant treatment in post-menopausal patients with OR/PR+ LABC. In this single-centre study involving 24 patients treated for three months, no significant differences in objective response (clinically assessed) between the two doses were observed. The safety profile was acceptable both in the group of patients treated with letrozole $2.5 \mathrm{mg}$ (in which the mean age was 77.6 years and the age range 61-87) and in the group treated with the $10 \mathrm{mg}$ dose (mean age 71.6, range 52-84).
On the basis of some evidence that human epidermal growth factor receptor-2 (HER2) overexpression may confer resistance to tamoxifen in OR/PR+ breast tumours, ${ }^{33,34}$ and overexpression of HER1 as well as, ${ }^{35}$ a biomarker subanalysis of the P024 study was carried out to analyse the relationship between the expression of HER1 and HER2 and the response to letrozole. A significantly higher response rate was observed in patients with OR/PR+, HER2+ and HER1+ breast tumours treated with letrozole compared with patients treated with tamoxifen ( $88 \%$ versus $21 \%, p=0.0004$ ). Letrozole was equally effective in HER2+ and HER2- tumours. These data suggest that pre-operative letrozole could be an effective alternative to tamoxifen in OR/PR+, HER2+ and HER1+ breast tumours. ${ }^{36}$

\section{Anastrozole}

Anastrozole (2,2'-[5-(1H-1,2,4-triazol-1-ylmethyl)-1,3-phenylene]bis (2-methylpropanenitrile) is an orally administered competitive non-steroidal aromatase enzyme inhibitor.

In a Phase II clinical trial, Milla-Santos et al. reported a high antitumour activity of pre-operative anastrozole in post-menopausal patients with hormone-dependent breast tumours. One hundred and twelve patients with a median age of 64.7 years (range 56-73) received anastrozole $1 \mathrm{mg}$ for three months; an objective response rate (ORR) of $83 \%$ and a low incidence of side effects were reported. ${ }^{37}$

Consistent with previous findings, Dixon et al. observed that pre-operative anastrozole was able to induce a median reduction in tumour volume (detected on ultrasound) of $\geq 75 \%$ (95\% confidence interval 51-79) in a majority of 24 women treated with anastrozole given at a daily dose of $1 \mathrm{mg}$ or $10 \mathrm{mg}$ for 12 weeks. ${ }^{38}$

Moreover, two randomised controlled trials evaluated the neoadjuvant use of anastrozole. In the Pre-operative Arimidex ${ }^{\circledR}$ compared to tamoxifen (PROACT) study, anastrozole was compared with tamoxifen as a pre-operative treatment for post-menopausal women with $\mathrm{OR} / \mathrm{PR}+$ operable $(\mathrm{T} 2 / 3, \mathrm{NO}-2, \mathrm{MO})$ or potentially operable (T4b, NO-2, MO) breast cancer. Concomitant chemotherapy was also permitted. The hormonal therapy-only subpopulation (314 out of 451 patients) was randomised to receive either anastrozole or tamoxifen alone for three months. ${ }^{39}$ The ORR, assessed using both ultrasound and calliper, was slightly higher with anastrozole compared with tamoxifen, although not statistically different $(36.2 \%$ versus $26.5 \%, p=0.07$ and $49.7 \%$ versus $39.7 \%, p=0.08$, respectively). On the other hand, anastrozole significantly improved surgery rates in patients deemed amenable to surgery at baseline ( $43.0 \%$ versus $30.8 \%, p=0.04$ ).

Similar results were obtained in the Immediate preoperative anastrozole, tamoxifen, or combined with tamoxifen (IMPACT) trial, ${ }^{23}$ in which 330 women (median age 73 years) were randomly assigned to be treated with anastrozole or tamoxifen or a combination of the two for 12 weeks before surgery. A significant difference in clinical ORR and in $\mathrm{BCS}$ rate was not reached between the three groups. However, a trend in favour of anastrozole compared with tamoxifen was reported among patients with OR+ and HER2+ tumours (the ORR for patients with HER2+ cancer was $58 \%$ for anastrozole versus $22 \%$ for tamoxifen [ $p=0.18]$ ). Results do reinforce the hypothesis that Als may be more effective than tamoxifen in the treatment of OR+ early breast cancer that also overexpresses HER2, and the lack of significance could be due to the small patient numbers and underpowered design of the study. 
Table 1: Activity/Efficacy of Aromatase Inhibitors in Neoadjuvant Setting

\begin{tabular}{|c|c|c|c|c|c|}
\hline Study & Drug & $\mathrm{n}$ & Phase & Median Age (Years) & $\begin{array}{l}\text { Objective Response } \\
\text { Rate (\%) }\end{array}$ \\
\hline Mustacchi et al., $2009^{40}$ & Exemestane & 117 & $\|$ & 80 & 69.6 \\
\hline Mlineritsch et al., $2008^{41}$ & Exemestane & 80 & $\|$ & 71 & $34^{*}$ \\
\hline Takei et al., $2008^{42}$ & Exemestane & 44 & $\|$ & 60 & $66^{*}$ \\
\hline Toi et al., $2011^{43}$ & Exemestane & 116 & $\|$ & 64 & 51 (after 24 weeks) \\
\hline Krainick et al., $2003^{44}$ & Exemestane & 27 & $\|$ & 71 & 40 \\
\hline Tubiana-Hulin et al., $2007^{45}$ & Exemestane & 45 & $\|$ & 67.6 & $73.3^{\star}$ \\
\hline Semiglazov et al., $2005^{46}$ & Exemestane versus tamoxifen & 151 & ॥ & Not reported & 76.3 versus $40(p=0.05)$ \\
\hline Barnadas et al., $2009^{47}$ & Exemestane & 55 & ॥ & 76 & $61 *$ \\
\hline Krainick-Strobel et al., $2008^{48}$ & Letrozole & 32 & $\|\mathrm{lb} /\| \mathrm{I}$ & Not reported & 71.9 \\
\hline Eiermann et al., $2001^{25}$ & Letrozole versus tamoxifen & 154 versus 170 & III & 68 versus 67 & 55 versus $36(p<0.001)$ \\
\hline Dixon et al., $2001^{32}$ & Letrozole $2.5 \mathrm{mg}$ versus letrozole $10 \mathrm{mg}$ & 12 versus 12 & $\|\mathrm{lb} /\| \mathrm{I}$ & 77.6 versus 71.6 & Not reported \\
\hline Milla-Santos et al., $2004^{37}$ & Anastrozole & 112 & $\|$ & 64.7 & 83 \\
\hline Dixon et al., $2000^{38}$ & $\begin{array}{l}\text { Anastrozole } 1 \mathrm{mg} \text { versus } \\
\text { anastrozole } 10 \mathrm{mg}\end{array}$ & 13 versus 13 & $\| \mathrm{b}$ & Not reported & 91 \\
\hline Cataliotti et al., $2006^{39}$ & Anastrozole versus tamoxifen & $\begin{array}{l}228 \text { versus } 223 \\
\left(163 \text { versus } 151^{\star *}\right)\end{array}$ & III & 67.3 versus 66.7 & $\begin{array}{l}50 \text { versus } 46.2(p=0.37) \\
(49.7 \text { versus } \\
\left.39.7^{\star}, p=0.08\right)\end{array}$ \\
\hline Smith et al., $2005^{23}$ & $\begin{array}{l}\text { Anastrozole versus tamoxifen versus } \\
\text { combination }\end{array}$ & $\begin{array}{l}113 \text { versus } \\
108 \text { versus } 109\end{array}$ & III & $\begin{array}{l}73.2 \text { versus } 71.5 \\
\text { versus } 73.2\end{array}$ & 37 versus 36 versus $39 *$ \\
\hline Ellis et al., $2011^{20}$ & $\begin{array}{l}\text { Exemestane versus letrozole } \\
\text { versus anastrozole }\end{array}$ & $\begin{array}{l}124 \text { versus } 127 \\
\text { versus } 123\end{array}$ & $\| \mathrm{b}$ & $\begin{array}{l}69 \text { versus } 65 \\
\text { versus } 65\end{array}$ & $\begin{array}{l}62.9 \text { versus } 74.8 \\
\text { versus } 69.1\end{array}$ \\
\hline Brunello et al., $2011^{49}$ & Anastrozole, letrozole, exemestane & 66 & Retrospective & 82 & $86.4^{*}$ \\
\hline Dixon et al., $2010^{50}$ & Letrozole & $79 \S$ & Retrospective & 81 & 65 and $43 \S \S$ \\
\hline
\end{tabular}

* Calliper assessment; ** Endocrine therapy-only patients; ${ }^{\S}$ Frail patients; ${ }^{\S} \S$ Reported progression-free survival at 2 and 5 years.

\section{Exemestane}

Exemestane (6-methylideneandrosta-1,4-diene-3,17-dione) is an irreversible steroidal aromatase inactivator, structurally related to the natural substrate androstenedione. It is administered orally. Primary use of exemestane has been evaluated in several studies, mainly Phase II trials. ${ }^{40-43}$ Overall response rates are consistently high, with more than two-thirds of patients worldwide experiencing partial responses.

In a small Phase $\|$ trial with in vivo correlative studies, it was demonstrated that neoadjuvant exemestane causes shrinkage of tumours in more than $80 \%$ of patients, along with markedly reducing cellular proliferation and progesterone receptor expression. ${ }^{18}$

In the German neoadjuvant Aromasin ${ }^{\circledR}$ initiative (GENARI) trial, patients with a median age of 71 years received exemestane for four months prior to surgery. Overall response rates were about $40 \%$, and more than half the patients were eventually treated with BCS. ${ }^{44}$ The most frequently reported toxicity was hot flushes.

In a French study, patients with a median age of 67 years were given exemestane for 4-5 months prior to surgery. ${ }^{45}$ In this study, more than two-thirds of patients experienced a response. BCS was performed in $31(45.2 \%)$ patients. No grade 3 or 4 toxicities were observed.

In a Russian study, exemestane was compared with tamoxifen. One hundred and fifty-one women with hormone receptor-positive breast cancer were randomised to receive either tamoxifen or exemestane for three months. ${ }^{46}$ While the clinical ORR was greater for exemestane (76.3 \%) than for tamoxifen $(40.0 \%, p=0.05)$, similar outcomes were found in the two arms of the study in terms of objective response assessed on ultrasound and mammograms. More patients in the exemestane group went on to have BCS than in the tamoxifen group (36.8 \% versus $20.0 \%, p=0.05$ ). Both treatments were well tolerated.
In a recently published Spanish Phase II trial, ${ }^{47} 55$ patients with OR+ breast cancer ineligible for BCS at baseline (mean age 76 years) were recruited to receive oral exemestane $25 \mathrm{mg}$ daily for six months. Tumour response was evaluated by clinical examination, mammography and breast ultrasound every two months. Overall clinical response to treatment was observed in $61 \%$ of patients. The median time to surgery from the beginning of treatment was seven months. BCS was eventually performed in more than half the patients, $34.5 \%$ underwent to mastectomy and $21 \%$ did not undergo surgery, either because they chose not or because the physician did not consider them to be suitable. No severe adverse events were detected.

An Italian study by Mustacchi et al. ${ }^{40}$ specifically looked at elderly patients. The median age of the 117 patients enrolled was 80 years. The overall response rate, assessed by means of either clinical and radiological or clinical-only evaluation, was $69.6 \%$. Surgery was then performed in two-thirds of patients.

\section{Comprehensive Geriatric Assessment}

There is general agreement that evaluation of breast cancer-related mortality risk and of other patient-related factors, such as functional status, co-morbidities, cognition and psychosocial issues, is to be assessed to individualise treatment for older patients.

Comprehensive geriatric assessment (CGA) is a multidisciplinary evaluation of the older patient which allows identification and classification of clinical/functional conditions in elderly patients, integrating information on various domains such as disability, co-morbidity, cognitive status, presence of depression, social and economic status and other conditions which may influence the global health status of elderly subjects, in order to develop a comprehensive plan of assistance and treatment which takes into account the effective needs of older patients ${ }^{51}$ and their expectations. ${ }^{52}$ 
- 'fit' patients, which includes subjects presenting no limitation in activities of daily living (ADLS) and with no major co-morbidity, who present rough mortality rates at two years of 8-12\%;

- 'frail' patients, who are patients older than 85 years or those presenting with severe co-morbidity or functional dependence in ADLs, or with geriatric syndromes (dementia, delirium, severe osteoporosis, depression, failure to thrive, inability to gain weight, falls, incontinence), with mortality rates higher than $40 \%$; and

- In between are the majority of elderly patients defined as 'vulnerable', who are dependent in some instrumental activities of daily living (IADLS), but not in ADLs, or who present manageable co-morbidity with appropriate treatment; their mortality rates are approximately $16-25 \%$ at two years. ${ }^{53}$

Generally, elderly patients who are deemed frail at the CGA have a rough two-year mortality of $40 \%$ independently of the diagnosis of cancer; therefore recommendations have been made to deliver only best supportive care. ${ }^{53}$

Several studies on CGA show that for patients with breast cancer functional status is indeed a predictive factor for survival, for mortality and for toxicity from treatments. ${ }^{54,55}$

Severe osteoporosis or severe dyslipidaemia may in some cases contraindicate treatment with Als. CGA, and in particular careful detection of co-morbidity, could be a useful tool in such cases for selection of patients that could derive benefit from endocrine treatment with tamoxifen instead of Als.

Given these considerations, the approach to older adults with breast cancer must include a multidimensional comprehensive geriatric evaluation in order to unveil potential weakness that may result in severe toxicity or complications from treatment and to maximise benefits. ${ }^{56}$

On this view, endocrine therapy may be a good option for those patients having large OR/PR+ breast tumours in which immediate surgery may lead to functional impairment or may be contraindicated, and chemotherapy may result in unacceptable toxicities.

\section{Treatment duration - Primary and Definitive Treatment}

A critical question about neoadjuvant treatment with an Al is for how Iong to treat in the pre-operative setting. To date, there is no defined median treatment duration.

Usually, neoadjuvant endocrine treatment is prolonged for 3-4 months before surgery. ${ }^{11,23,25,32,38,39,45,47,48}$ According to the study by Krainick-Strobel et al., a minimum of four months of therapy is necessary, yet a longer duration of treatment may lead to better results. In this study, which specifically addressed the question of pre-operative treatment duration, 32 patients were treated with letrozole $2.5 \mathrm{mg}$ orally daily for 4-8 months and clinical and radiological tumour response was evaluated. Unfortunately, the trial was stopped prematurely due to slow recruitment, but available data support the consideration that prolonged treatment for up to eight months rather than an early interruption after four months can result in further tumour volume reduction in some patients. ${ }^{48}$
To date, conclusive data on the optimal duration of pre-operative endocrine treatments for OR/PR+ breast cancer in post-menopausal women are still not available.

Recommendation from the panel of experts at the St Gallen consensus conference held in 2011 are for the continuation of treatment until maximum response is obtained, or for a minimum of 4-8 months. ${ }^{57}$

In some cases, given the high response rate reached with Als, some elderly patients ( $\geq 70$ years old) may be spared surgery. A review of seven randomised trials showed no difference in OS for patients undergoing primary endocrine therapy with tamoxifen when compared with surgery, with or without tamoxifen. ${ }^{28}$ However, the patients who underwent surgery experienced a lower rate of relapse; therefore a recommendation can be made that primary endocrine therapy with tamoxifen should be suggested if patients are unfit for surgery. However, only scarce data are available for primary, definitive treatment with third-generation Als.

In most of the studies of neoadjuvant endocrine treatment, the majority of patients were then treated with surgery. ${ }^{23,58}$ However, there are some data from retrospective studies specifically addressed to elderly patients in which response rates with the use of Als as neoadjuvant treatment are fairly high and survival rates are quite encouraging, despite the fact that surgery was performed only in a minority of cases. ${ }^{49,50}$

In a small Scottish study, ${ }^{50}$ most patients were deemed frail and therefore not candidates for surgery. However, PFS rates were $65 \%$ and $43 \%$, respectively, at 2 and 5 years from beginning of treatment with letrozole, with OS at 2 years of $76 \%$, at 5 years of $32 \%$.

In an Italian study by Brunello et al., ${ }^{49}$ a large proportion of patients $(57.6 \%)$ were deemed frail following the CGA; at two and five years, PFS rates were $95 \%$ and $85 \%$ and OS rates were $95 \%$ and $64 \%$, respectively. Less than half received further antineoplastic treatments and only with endocrine drugs. In this study, surgery was eventually performed in $10 \%$ of patients only.

A possible suggestion is therefore that, depending on the results of CGA, surgery may be omitted without significantly compromising PFS and OS in frail or unfit patients.

\section{Conclusions}

Since the optimal endocrine treatment schedule remains to be determined, prospective observational and randomised studies are needed to better assess not only the clinical benefit of neoadjuvant treatment with Als but also resistance which may develop in case it is administered as 'definitive' treatment. Furthermore, possible risks correlated with long-term use such as osteoporosis, which could affect morbidity and mortality beyond oncological disease, need to be investigated. ${ }^{59}$

In the effort to optimise treatment for elderly patients, we should promote the conduction of such studies specifically addressed to the elderly using standardised tools of assessment in order to weigh the benefits achieved with treatment, such as tumour response, against quality of life and preservation of functional autonomy, which remain the most relevant outcome measure in unfit elderly patient. 
1. Ferlay J, Shin HR, Bray F, et al., Estimates of worldwide burden of cancer in 2008: GLOBOCAN 2008, Int I Cancer, 2010;127:2893-2917.

2. Sader $C$, Ingram $D$, Hastrich $D$, Management of breast cancer in the elderly by complete local excision and tamoxifen alone, Aust N Z J Surg, 1999;69:790-3.

3. Wanebo $\mathrm{HJ}$, Cole B, Chung M, et al., Is surgica management compromised in elderly patients with breast cancer?, Ann Surg, 1997;225:579-86, discussion 586-9.

4. Hutchins LF, Unger JM, Crowley JJ, et al., Underrepresentation of patients 65 years of age or older in cancer-treatment trials, N Eng/ J Med, 1999;341:2061-7.

5. Lewis JH, Kilgore ML, Goldman DP, et al., Participation of patients 65 years of age or older in cancer clinical trials, J Clin Oncol, 2003:21:1383-9.

6. Talarico L, Chen G, Pazdur R, Enrollment of elderly patients in clinical trials for cancer drug registration: a 7 -year experience by the US food and drug administration, I Clin Oncol, 2004;22:4626-31.

7. Carlson RW, Moench S, Hurria A, et al., NCCN task force report: Breast cancer in the older woman, I Natl Compr Canc Netw, 2008;6(Suppl. 4):S1-25, quiz S26-7.

8. Newman LA, Epidemiology of locally advanced breast cancer, Semin Radiat Oncol, 2009:19:195-203.

9. Becker N, Breast cancer epidemiology. In: Jatoi I, Kaufman $M$ (eds), Management of Breast Diseases, New York: Springer, 2010;121-30

10. Anderson WF, Chu KC, Chang S, Inflammatory breast carcinoma and noninflammatory locally advanced breas carcinoma: distinct clinicopathologic entities?, J Clin Oncol, 2003;21:2254-9

11. Semiglazov VF, Semiglazov VV, Dashian GA, et al., [Phase ॥ clinical trial of neoadjuvant hormone therapy in comparison with chemotherapy of patients with breast cancerl, Vopr Onkol, 2007:53:400-8.

12. Wyld L, Garg DK, Kumar ID, et al., Stage and treatment variation with age in postmenopausal women with breast cancer: compliance with guidelines, Br J Cancer 2004;90:1486-91.

13. Bergman $L$, van Dongen JA, van Ooijen B, van Leeuwen FE, Should tamoxifen be a primary treatment choice for elderly breast cancer patients with locoregional disease? Breast Cancer Res Treat, 1995:34:77-83.

14. Gazet JC, Ford HT, Gray R, et al., Estrogen-receptordirected neoadjuvant therapy for breast cancer: Results of a randomised trial using formestane and methotrexate, mitozantrone and mitomycin C (MMM) chemotherapy, Ann Oncol, 2001;12:685-91.

15. Willsher PC, Robertson JFR, Jackson L, et al., Investigation of primary tamoxifen therapy for elderly patients with operable breast cancer, Breast, 1997;6:150-4.

16. Macaskill EJ, Renshaw L, Dixon JM, Neoadjuvant use of hormonal therapy in elderly patients with early or locally advanced hormone receptor-positive breast cancer, oncologist, 2006;11:1081-8.

17. Chia YH, Ellis MJ, Ma CX, Neoadjuvant endocrine therapy in primary breast cancer: Indications and use as a research tool, Br J Cancer, 2010;103:759-64.

18. Miller WR, Dixon JM, Endocrine and clinical endpoints of exemestane as neoadjuvant therapy, Cancer Control, 2002;9:9-15

19. Coombes $\mathrm{RC}$, Hall E, Gibson $\mathrm{LJ}$, et al., A randomized trial of exemestane after two to three years of tamoxifen therapy in postmenopausal women with primary breast cancer, N Engl J Med, 2004;350:1081-92.

20. Ellis MJ, Suman VJ, Hoog J, et al., Randomized phase ॥ neoadjuvant comparison between letrozole, anastrozole, and exemestane for postmenopausal women with estrogen receptor-rich stage 2 to 3 breast cancer: Clinical and biomarker outcomes and predictive value of the baseline PAM50-based intrinsic subtype - ACOSOG Z1031, I Clin Oncol, 2011;29:2342-9.

21. Thürlimann B, Keshaviah A, Mouridsen H, BIG 1-98: Randomized double-blind phase III study to evaluate letrozole (L) vs tamoxifen (T) as adjuvant endocrine therapy for postmenopausal women with receptorpositive breast cancer, Amer Soc Clin Oncol, 2005;511.

22. Howell A, Cuzick J, Baum M, et al., Results of the ATAC (arimidex, tamoxifen, alone or in combination) trial afte completion of 5 years' adjuvant treatment for breast cancer, Lancet, 2005;365:60-2

23. Smith IE, Dowsett $M$, Ebbs SR, et al., Neoadjuvan treatment of postmenopausal breast cancer with anastrozole, tamoxifen, or both in combination: the immediate preoperative anastrozole, tamoxifen, or combined with tamoxifen (IMPACT) multicenter doubleblind randomized trial, I Clin Oncol, 2005;23:5108-16.

24. Ellis MJ, Ma C, Letrozole in the neoadjuvant setting: the P024 trial, Breast Cancer Res Treat, 2007;105(Suppl. 1): 33-43.

25. Eiermann W, Paepke S, Appfelstaedt J, et al., Preoperative treatment of postmenopausal breast cancer patients with letrozole: a randomized double-blind multicenter study, Ann Oncol, 2001;12:1527-32.

26. Gibson L, Lawrence D, Dawson C, Bliss J, Aromatase inhibitors for treatment of advanced breast cancer in postmenopausal women, Cochrane Database Syst Rev, 2009;(4):CD003370

27. Seo JH, Kim YH, Kim JS, Meta-analysis of pre-operative aromatase inhibitor versus tamoxifen in postmenopausal woman with hormone receptor-positive breast cancer, Cancer Chemother Pharmacol, 2009;63:261-6.

28. Hind D, Wyld L, Beverley CB, Reed MW, Surgery versus primary endocrine therapy for operable primary breast cancer in elderly women (70 years plus), Cochrane Database Syst Rev, 2006;(1):CD004272

29. Mouridsen $H$, Gershanovich $M$, Sun $Y$, et al., Superio efficacy of letrozole versus tamoxifen as first-line therapy for postmenopausal women with advanced breast cance results of a phase III study of the international letrozole breast cancer group, I Clin Oncol, 2001;19:2596-606.

30. Mouridsen $\mathrm{H}$, Gershanovich $\mathrm{M}$, Sun $\mathrm{Y}$, et al., Phase III study of letrozole versus tamoxifen as first-line therapy of advanced breast cancer in postmenopausal women: Analysis of survival and update of efficacy from the international letrozole breast cancer group, I Clin Oncol, 2003:21:2101-9.

31. Eiermann W, Paepke S, Appfelstaedt J, et al., Preoperativ treatment of postmenopausal breast cancer patients with letrozole: a randomized double-blind multicenter study Ann Oncol, 2001;12:1527-32.

32. Dixon JM, Love CD, Bellamy CO, et al., Letrozole as primary medical therapy for locally advanced and large operable breast cancer, Breast Cancer Res Treat 2001;66:191-9

33. De Laurentiis $M$ Arpino $G$ Massarelli $E$, et al A metaanalysis on the interaction between HER-2 expression and response to endocrine treatment in advanced breast cancer, Clin Cancer Res, 2005;11:4741-8.

34. Carlomagno C, Perrone F, Gallo C, et al., C-erb B2 overexpression decreases the benefit of adjuvant tamoxifen in early-stage breast cancer without axillary Iymph node metastases, I Clin Oncol, 1996;14:2702-8.

35. Newby JC, Johnston SR, Smith IE, Dowsett M, Expression of epidermal growth factor receptor and c-erbB2 during the development of tamoxifen resistance in human breast cancer, Clin Cancer Res, 1997:3:1643-51.

36. Ellis MJ, Coop A, Singh B, et al., Letrozole is more effective neoadjuvant endocrine therapy than tamoxifen for ErbB-1and/or ErbB-2-positive, estrogen receptor-positive primary breast cancer: Evidence from a phase III randomized trial J Clin Oncol, 2001;19:3808-16.

37. Milla-Santos A, Milla L, Calvo N, et al., Anastrozole as neoadjuvant therapy for patients with hormonedependent, locally-advanced breast cancer, Anticancer Res, 2004;24:1315-8.

38. Dixon JM, Renshaw L, Bellamy $C$, et al., The effects of neoadjuvant anastrozole (arimidex) on tumor volume in postmenopausal women with breast cancer: a randomized, double-blind, single-center study, Clin Cancer Res, 2000;6:2229-35

39. Cataliotti L, Buzdar AU, Noguchi S, et al., Comparison of anastrozole versus tamoxifen as preoperative therapy in postmenopausal women with hormone receptor-positive breast cancer: the Pre-Operative "Arimidex" Compared to Tamoxifen (PROACT) trial, Cancer, 2006;106:2095-2103.

40. Mustacchi G, Mansutti M, Sacco C, et al., Neo-adjuvan exemestane in elderly patients with breast cancer: a phase II, multicentre, open-label, Italian study, Ann oncol, 2009;20:655-9.

41. Mlineritsch B, Tausch C, singer C, et al., Exemestane as primary systemic treatment for hormone receptor positive post-menopausal breast cancer patients: A phase II trial of the Austrian breast and colorectal cancer study group (ABCSG-17), Breast Cancer Res Treat, 2008;112:203-13.

42. Takei H, Suemasu K, Inoue K, et al., Multicenter phase II trial of neoadjuvant exemestane for postmenopausal patients with hormone receptor-positive, operable breast cancer: Saitama breast cancer clinical study group (SBCCSG-03), Breast Cancer Res Treat, 2008;107:87-94.

43. Toi M, Saji S, Masuda N, et al., Ki67 index changes, pathological response and clinical benefits in primary breast cancer patients treated with 24 weeks of aromatase inhibition, Cancer Sci, 2011:102:858-65.

44. Krainick U, Astner A, Jonat W, Wallwiener D, Phase II study to define safety and efficacy of exemestane as preoperative therapy for postmenopausal patients with primary breast cancer - final results of the German neoadjuvant aromasin initiative (GENARI), Breast Cancer Res Treat, 2003;82(Suppl. 1):S55.

45. Tubiana-Hulin M, Becette V, Bieche I, et al., Exemestane as neoadjuvant hormonotherapy for locally advanced breast cancer: Results of a phase II trial, Anticancer Res, 2007;27:2689-96

46. Semiglazov VF, Semiglazov VV, Ivanov VG, et al., Exemestane (E) vs tamoxifen (T) as neoadjuvant endocrine therapy for postmenopausal women with ER+ breast cancer (T2N1-2, T3NO-1, T4NOMO), I Clin Oncol, 2005;23(Suppl. 16):11S, Abstract 530.

47. Barnadas A, Gil M, González S, et al., Exemestane as primary treatment of oestrogen receptor-positive breast cancer in postmenopausal women: a phase II trial, Br J Cancer, 2009;100:442-9.

48. Krainick-Strobel UE, Lichtenegger W, Wallwiener $\mathrm{D}$, et al., Neoadjuvant letrozole in postmenopausal estrogen and/or progesterone receptor positive breast cancer: A phase IIb/III trial to investigate optimal duration of preoperative endocrine therapy, BMC Cancer, 2008;8:62.

49. Brunello A, Monfardini S, Falci C, et al., Aromatase inhibitors as neoadjuvant treatment in elderly patients (>70 years) with locally advanced breast cancer: a monoinstitutional experience, Eur J Cancer 2011;47:S278-S279.

50. Dixon JMJ, Renshaw L, Keys J, et al., Outcome of frail elderly patients treated with letrozole alone, Cancer Res, 2010;70(24 Suppl.):175s, Abstract P1-12-06.

51. Pal SK, Katheria V, Hurria A, Evaluating the older patient with cancer: understanding frailty and the geriatric assessment, CA Cancer I Clin, 2010;60:120-32

52. Albrand G, Terret C, Early breast cancer in the elderly: assessment and management considerations, Drugs Aging, 2008;25:35-45

53. Balducci L, Yates J, General guidelines for the management of older patients with cancer, oncology (Williston Park), 2000;14:221-7.

54. Basso U, Falci C, Brunello A, et al., Prognostic value of multidimensional geriatric assessment (MGA) on surviva of a prospective cohort of 880 elderly cancer patients, I Clin Oncol, 2011;29(Suppl.):Abstract 9065.

55. Freyer G, Geay JF, Touzet S, et al., Comprehensive geriatric assessment predicts tolerance to chemotherapy and survival in elderly patients with advanced ovarian carcinoma: a GINECO study, Ann Oncol, 2005;16:1795-1800.

56. Klepin $H$, Mohile $S$, Hurria A, Geriatric assessment in older patients with breast cancer, I Natl Compr Canc Netw, 2009:7:226-36

57. Goldhirsch A, Wood WC, Coates AS, et al., Strategies for subtypesm - dealing with the diversity of breast cancer: highlights of the St. Gallen international expert consensus on the primary therapy of early breast cancer 2011, Ann Oncol, 2011;22:1736-47.

58. Mustacchi G, Ceccherini R, Milani S, et al., Tamoxifen alone versus adjuvant tamoxifen for operable breast cancer of the elderly: long-term results of the phase III randomized controlled multicenter GRETA trial, Ann Oncol, 2003; 14:414-20

59. Olson JA Jr. Budd GT, Carey LA, et al., Improved surgical outcomes for breast cancer patients receiving neoadjuvant aromatase inhibitor therapy: Results from a multicenter phase II trial, J Am Coll Surg, 2009;208:906-14; discussion $915-6$ 